\title{
Study of Thorium Fuel Cycles for Light Water Reactor VBER-150
}

\author{
Daniel Evelio Milian Lorenzo, ${ }^{1}$ Daniel Milian Pérez, ${ }^{1}$ Lorena Pilar Rodríguez García, ${ }^{1}$ \\ Jesús Salomón Llanes, ${ }^{1}$ Carlos Alberto Brayner de Oliveira Lira, ${ }^{2}$ \\ Manuel Cadavid Rodríguez, ${ }^{3}$ and Carlos Rafael García Hernández ${ }^{1}$ \\ ${ }^{1}$ Instituto Superior de Tecnologías y Ciencias Aplicadas (InSTEC), Avenida Salvador Allende y Luaces, Quinta de Los Molinos, \\ Plaza de la Revolución, 10400 La Habana, Cuba \\ ${ }^{2}$ Departamento de Energia Nuclear-UFPE, Cidade Universitária, Avenida Professor Luiz Freire 1000 Recife, PE, Brazil \\ ${ }^{3}$ Corporación Nuclear Eléctrica Chile S. A., (CNE Chile), Latadia, Las Condes, 4250 Santiago, Chile
}

Correspondence should be addressed to Daniel Evelio Milian Lorenzo; dmilian1954@gmail.com

Received 30 September 2013; Revised 11 November 2013; Accepted 12 November 2013

Academic Editor: Arkady Serikov

Copyright (C) 2013 Daniel Evelio Milian Lorenzo et al. This is an open access article distributed under the Creative Commons Attribution License, which permits unrestricted use, distribution, and reproduction in any medium, provided the original work is properly cited.

\begin{abstract}
The main objective of this paper is to examine the use of thorium-based fuel cycle for the transportable reactors or transportable nuclear power plants (TNPP) VBER-150 concept, in particular the neutronic behavior. The thorium-based fuel cycles included $\mathrm{Th}^{232}+\mathrm{Pu}^{239}, \mathrm{Th}^{232}+\mathrm{U}^{233}$, and $\mathrm{Th}^{232}+\mathrm{U}$ and the standard design fuel UOX. Parameters related to the neutronic behavior such as burnup, nuclear fuel breeding, MA stockpile, and Pu isotopes production (among others) were used to compare the fuel cycles. The $\mathrm{Pu}$ transmutation rate and accumulation of $\mathrm{Pu}$ with $\mathrm{MA}$ in the spent fuel were compared mutually and with an UOX open cycle. $T h e \mathrm{Th}^{232}+\mathrm{U}^{233}$ fuel cycle proved to be the best cycle for minimizing the production of $\mathrm{Pu}$ and MA. The neutronic calculations have been performed with the well-known MCNPX computational code, which was verified for this type of fuel performing calculation of the IAEA benchmark announced by IAEA-TECDOC-1349.
\end{abstract}

\section{Introduction}

There is a growing interest in small reactors, and specifically TNPP. These reactors could represent a solution for developing countries with energy needs on islands, with remotely located areas without interconnected electricity grids or without the infrastructure required for land-based stationary NPP. Various designs have been developed, but most of the TNPP are based on long-term experience acquired with ship propulsion reactors and with larger land-based stationary reactors.

Depending on the host state requirements, the plant can be operated by the supplier state or by an entity from the receiving country. The host state can acquire a TNPP to own with all the consequences associated with the use of nuclear energy. In other scenario, the supplier state has additional responsibilities that may include delivery and return of the TNPP and its operation if requested by the host state. All operations with the nuclear fuel are done at the zone of responsibility of the supplier state. Anyway, to implement this, it is necessary to design a reactor core with long operation cycles without on-site reloading and shuffling of fuel, which ensures difficult access to the fuel during the entire period of the reactor installation operation including transportation. Some TNPP being considered today for export, but they are innovative concepts and need effort for the demonstration of their viability [1]. The use of thorium based fuel cycle and the exclusion of on-site refueling provides the solution to the nonproliferation problem; therefore, this category of reactors is very attractive for energy supplies in developing countries.

Thorium based fuel cycles are very attractive for producing long-term nuclear energy with low radiotoxicity waste $[2,3]$. Additionally, thorium fuel cycles could be done through the incineration of weapon grade plutonium $(\mathrm{WPu})$ or civilian plutonium $[4,5]$. Compared to the $\mathrm{U}^{238}-\mathrm{Pu}^{239}$ fuel cycle, $\mathrm{Th}^{232}-\mathrm{U}^{233}$ cycle produces less quantity of plutonium and minor actinides (MA: Np, Am, Cm), minimizing 
TABLE 1: $K_{\text {inf }}$ as function of burnup.

\begin{tabular}{lcccccc}
\hline Burnup, GWd/T & Russian Federation & Japan & Republic of Korea & India & Israel & MCNPX ver. 2.6e \\
\hline 0 & 1.1890 & 1.1987 & 1.1864 & 1.2076 & 1.1956 & $1.19775 \pm 0.00047$ \\
0.5 & 1.1569 & 1.1670 & 1.1551 & 1.1736 & 1.1643 & $1.16734 \pm 0.00048$ \\
20 & 1.0298 & 1.0521 & 1.0303 & 1.0372 & 1.0290 & $1.05898 \pm 0.00047$ \\
40 & 0.9147 & 0.9527 & 0.9167 & 0.9104 & 0.9119 & $0.95610 \pm 0.00041$ \\
60 & 0.8315 & 0.8657 & 0.8310 & 0.8294 & 0.8314 & $0.86561 \pm 0.00038$ \\
\hline
\end{tabular}

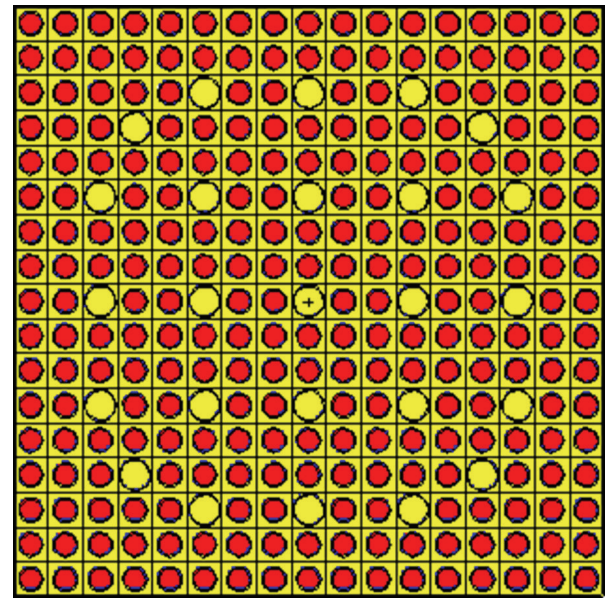

Figure 1: PWR fuel assembly model in MCNPX.

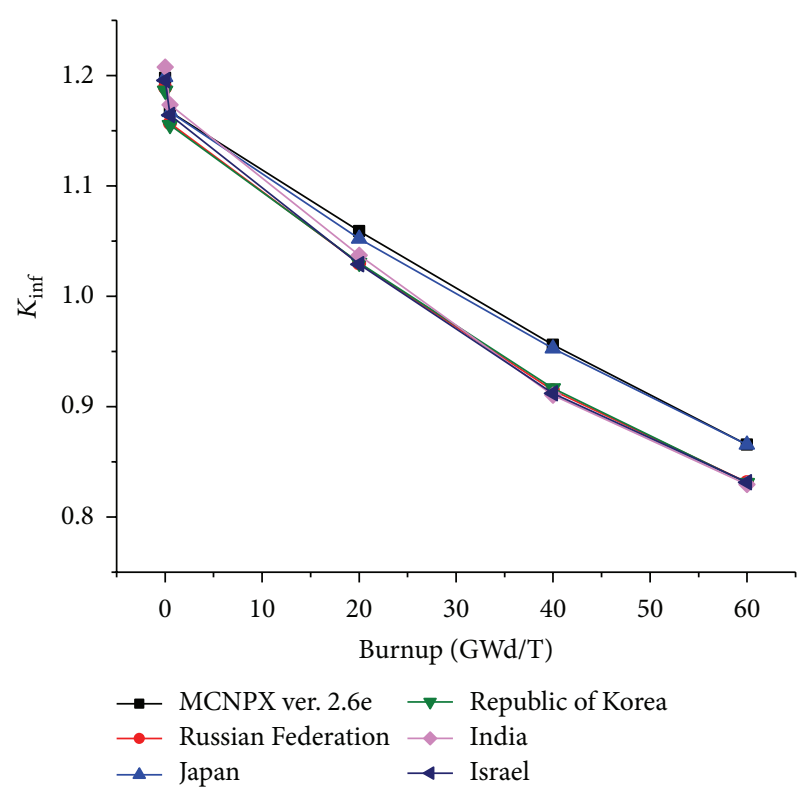

FIgURE 2: Comparison of $K_{\text {inf }}$ as function of burnup.

the radiotoxicity associated with spent fuel. Consequently, the production of radioactive waste in a thorium fuel cycle is lower than that in the U-Pu cycle used in traditional light water reactors (LWRs) [6].

The main objective of this paper is to examine the use of thorium based fuel cycle for the TNPP VBER-150 concept, in particular the neutronic behavior. The thorium based
TABLE 2: Main parameters of the TNPP VBER-150 concept.

\begin{tabular}{lc}
\hline Parameter & Value \\
\hline Thermal power (MWt) & 350 \\
Electrical power (MWe) & 110 \\
Core height $(\mathrm{m})$ & 2.2 \\
Core diameter $(\mathrm{m})$ & 2.42 \\
Core volume $\left(\mathrm{m}^{3}\right)$ & 9.02 \\
Coolant and moderator & $\mathrm{H}_{2} \mathrm{O}$ \\
Number of fuel assembly & 85 \\
Type of fuel assembly & Same as VVER-1000 \\
Power density $\left(\mathrm{MW} / \mathrm{m}^{3}\right)$ & 39 \\
Fuel mass (tons) & 22.3 \\
\hline
\end{tabular}

fuel cycles included $\mathrm{Th}^{232}+\mathrm{Pu}^{239}, \mathrm{Th}^{232}+\mathrm{U}^{233}, \mathrm{Th}^{232}+\mathrm{U}$, and the standard design fuel UOX. Parameters related to the neutronic behavior such as burnup, nuclear fuel breeding, MA stockpile, and $\mathrm{Pu}$ isotopes production (among others) were used to compare the fuel cycles. The thorium based fuel cycle was examined through computer simulations.

The neutronic calculations have been performed with the MCNPX version 2.6e code [7]. Unfortunately there is insufficient data of VVER reactors with fuel containing thorium to validate the MCNPX code version 2.6e code. To reach this goal and considering the scope of this paper we performed calculation of the IAEA benchmark announced by IAEA-TECDOC-1349 for a simplified model of a PWR assembly with a plutonium-thorium fuel composition [8]. Similar approach was proposed in [9]. The results obtained from MCNPX version 2.6e code are in good agreement with the results of other participants of this benchmark and the discrepancies can be caused by the use of various methods and nuclear database. The results of benchmark calculations ratified that MCNPX code version 2.6e with available library in XSDIR, ENDF/B VI.2, is adequate for studies of thorium based fuel cycles.

Three different models of VVER-1000 assemblies were designed for the MCNPX calculations with the purpose of selecting the model more suitable for the present study. To reach this goal the neutronic behavior of the reactor during the burnup and cycle duration for the three models was studied.

\section{The Reactor}

The TNPP VBER-150 concept is a two-loop modification of the VBER-300 reactor installation [10]. This nuclear reactor 


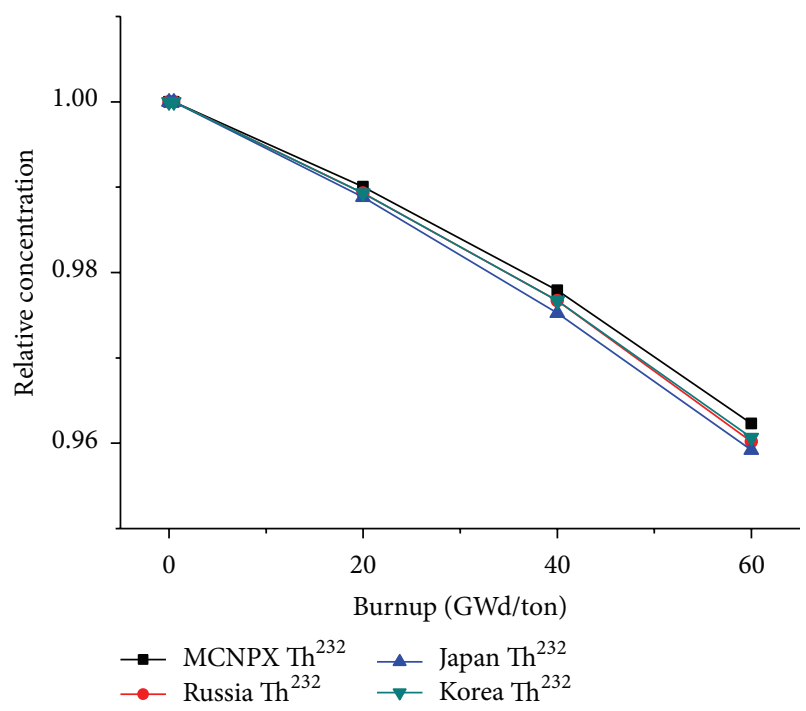

(a)

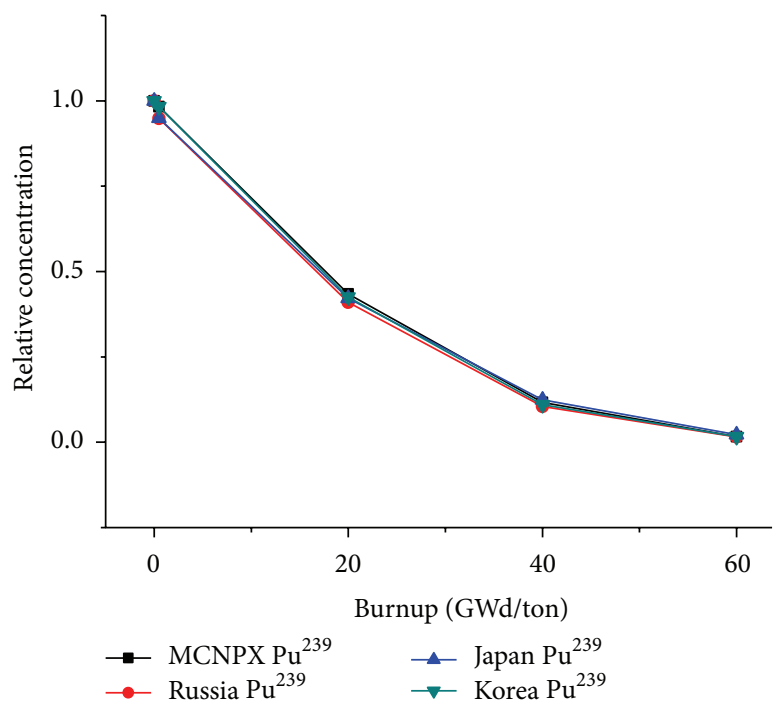

(b)

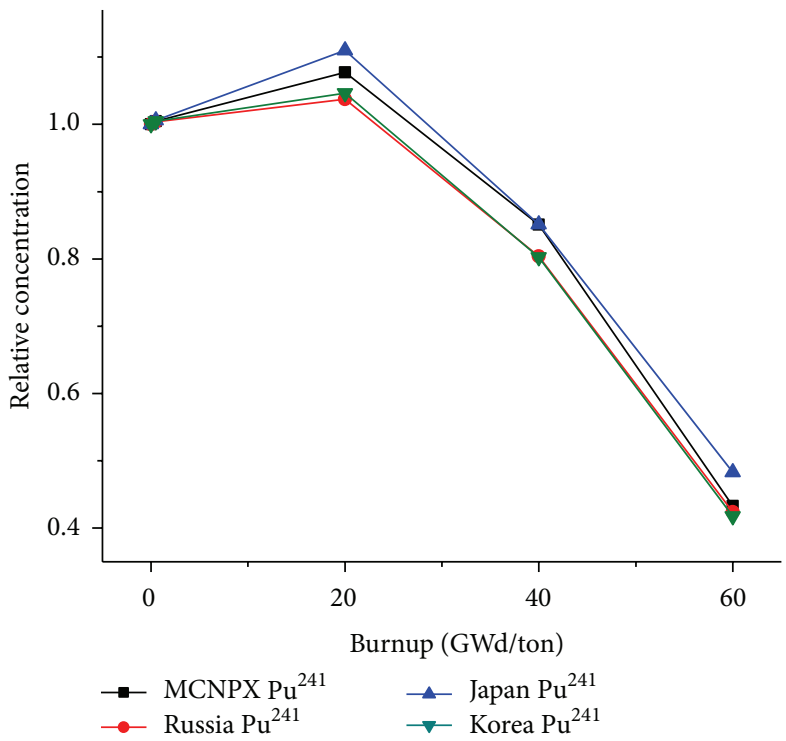

(c)

Figure 3: (a) Comparison of relative concentrations of $\mathrm{Th}^{232}$. (b) Comparison of relative concentrations of $\mathrm{Pu}^{239}$. (c) Comparison of relative concentrations of $\mathrm{Pu}^{241}$.

is a small sized loop type pressurized water reactor without on-site refueling for a floating NPP with cogeneration option. The nuclear fuel developed for the VVER reactors will be used for the VBER-150. Refueling, radioactive waste management and repairs could then be provided offsite, in special maintenance centers. Absence of on-site refueling ensures difficult access to the fuel during the entire period of the reactor installation operation including transportation. This TNPP concept is based on a successful multidecade experience in the production and operation of marine propulsion in the Russian Federation. Along with the VVER-type power reactors, the modular shipboard pressurized water reactors represent the most developed reactor technology; it is well examined and proven by successful operation. The total operating life of VVER-type reactors exceeded 1500 reactoryears, and over this period there were no events with the radiation-significant consequences. The operating experience of shipboard reactors exceeds 6000 reactor-years $[11,12]$.

\section{Computer Code Description}

The neutronic calculations have been performed with the MCNPX version 2.6e code with the available library in XSDIR, ENDF/B VI.2, on a standard personal computer with Intel(R) Core(TM) i3-2328 M CPU of $2.20 \mathrm{GHz}$ and $4 \mathrm{~GB}$ RAM. MCNPX code is based on the Monte Carlo method and incorporates new possibilities used in the present study, 
TABLE 3: Main results for the TNPP VBER-150 concept assembly models.

\begin{tabular}{lccc}
\hline Parameter & Model Figure 5(a) & Model Figure 5(b) & Model Figure 5(c) \\
\hline Initial $K_{\text {eff }}$ & $1.18813 \pm 0.00022$ & $1.21255 \pm 0.00021$ & $1.22083 \pm 0.00022$ \\
Full power days (FPD) & 1160 & 1178 & 1200 \\
Discharge burnup (GWd/T) & 17.27 & 17.46 & 18.03 \\
\hline
\end{tabular}

TABLE 4: Results for the considered fuel cycles.

\begin{tabular}{lccc}
\hline Parameter & \multicolumn{2}{c}{ Fuel cycles } & $\mathrm{Th}^{232}-\mathrm{U}$ \\
\hline Discharge burnup (GWd/T) & $\mathrm{Th}^{232}-\mathrm{Pu}^{239}$ & $\mathrm{Th}^{232}-\mathrm{U}^{233}$ & 18.03 \\
Full power days (FPD) & 26.29 & 39.06 & $\mathrm{UOX}$ \\
\hline
\end{tabular}

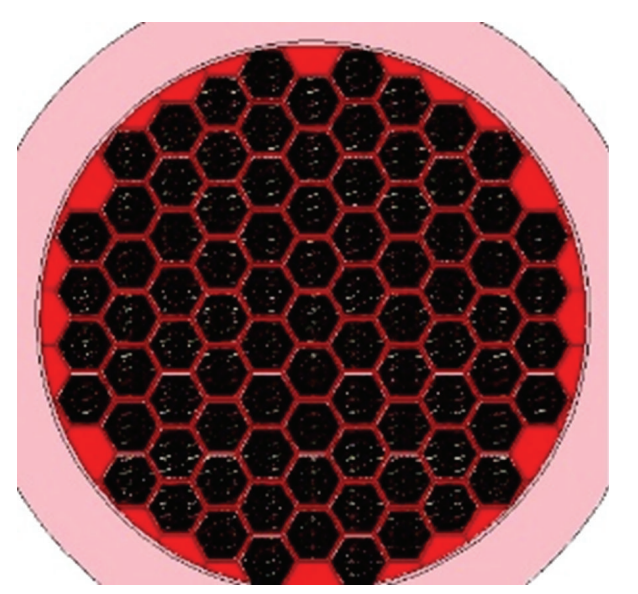

FIGURE 4: TNPP VBER-150 concept model in MCNPX.

such as depletion/burnup capability based on CINDER90, which works with a 63-energy-group structure. Crosssections for these 63 groups are condensed using a generic spectrum. CINDER90 utilizes decay and energy integrated reaction-rate probabilities along with fission yield information to calculate the temporal nuclide buildup and depletion. The library of data in CINDER90, residing in the CINDER.dat library file, includes isotope decay and interaction probability data for 3400 isotopes, including $~ 30$ fission yield sets and yield data for 1325 fission products.

The neutronics analysis performed in this work is the following:

(1) Calculate the IAEA benchmark announced by IAEATECDOC-1349. Compare the reactor physics parameters: $K_{\text {inf }}$ and fuel composition as a function of burnup, in a simplified model of a PWR assembly with a Plutonium-Thorium fuel composition.

(2) Calculate parameters related to the neutronic behavior as burnup and cycle duration for the three different models of VVER-1000 assemblies designed for the MCNPX calculations with the purpose of selecting the model more suitable for the present study.
TABLE 5: Reactor's BC for the fuel cycles studied.

\begin{tabular}{lc}
\hline Cycle & BC \\
\hline $\mathrm{Th}^{232}+\mathrm{Pu}^{239}$ & 0.50 \\
$\mathrm{Th}^{232}+\mathrm{U}^{233}$ & 0.51 \\
$\mathrm{Th}^{232}+\mathrm{U}$ & 0.55 \\
$\mathrm{UOX}$ & 0.70 \\
\hline
\end{tabular}

(3) Calculate parameters related to the neutronic behavior such as burnup, nuclear fuel breeding, MA stockpile, and $\mathrm{Pu}$ isotopes production (among others), for the TNPP VBER-150 concept.

The control parameters in the MCNPX calculations are the following:
Source size per cycle: 2000
Initial guess for $K$-infinite: 1.0
Number of settle cycles: 50
Total cycles to run: 1000
Total histories: 2,000,000.

\section{Benchmark}

The coordinated research project (CRP) "Potential of Thorium Based Fuel Cycles to Constrain Plutonium and to Reduce Long-term Waste Toxicity" examined different fuel cycle options in which plutonium can be recycled with thorium to incinerate the burner. The potential of the thoriummatrix was examined through computer simulations. Three benchmark tasks for different reactor concepts were performed in order to compare the effect of different methods and databases applied in the countries participating in the CRP. The agreement of the benchmark results generally was very satisfying [8].

The objective in this part of the present work was performing calculation of the IAEA benchmark announced by IAEA-TECDOC-1349 to verify that MCNPX code version 2.6e with available library in XSDIR, ENDF/B VI.2, is adequate for studies of thorium based fuel cycles. We performed calculation of the second benchmark. Five countries participated in this benchmark using its own methods 


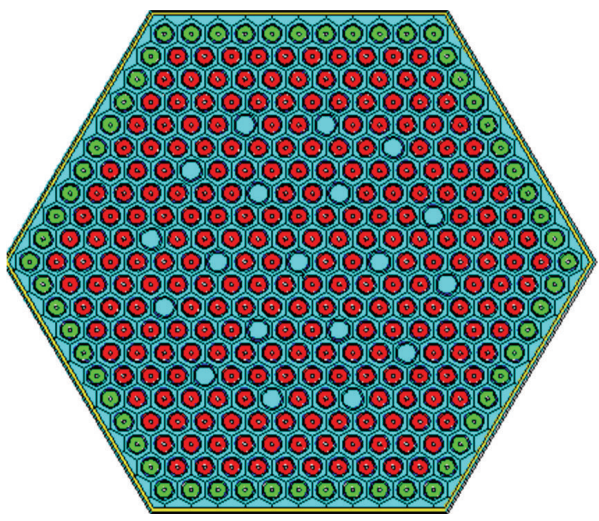

(2) Fuel element with thorium oxide

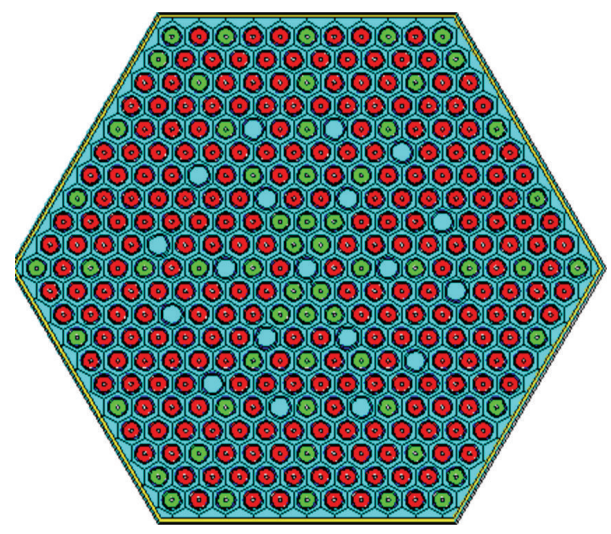

Fuel element with UOX

(a)

(b)

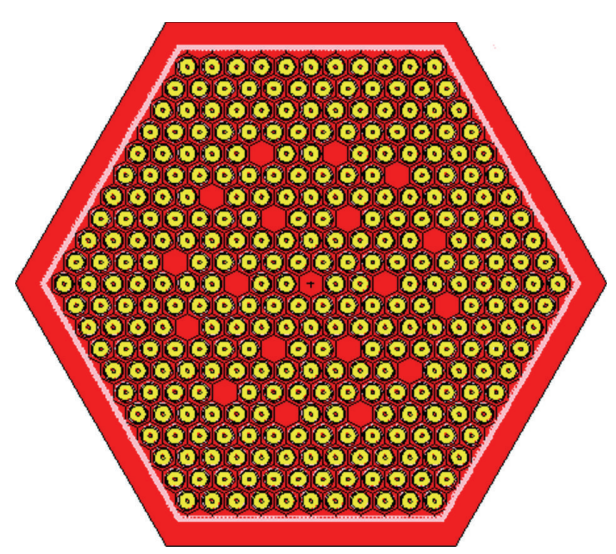

(c)

FIGURE 5: (a) and (b) TNPP VBER-150 concept advance fuel assembly model in MCNPX. (c) TNPP VBER-150 concept fuel assembly model in MCNPX.

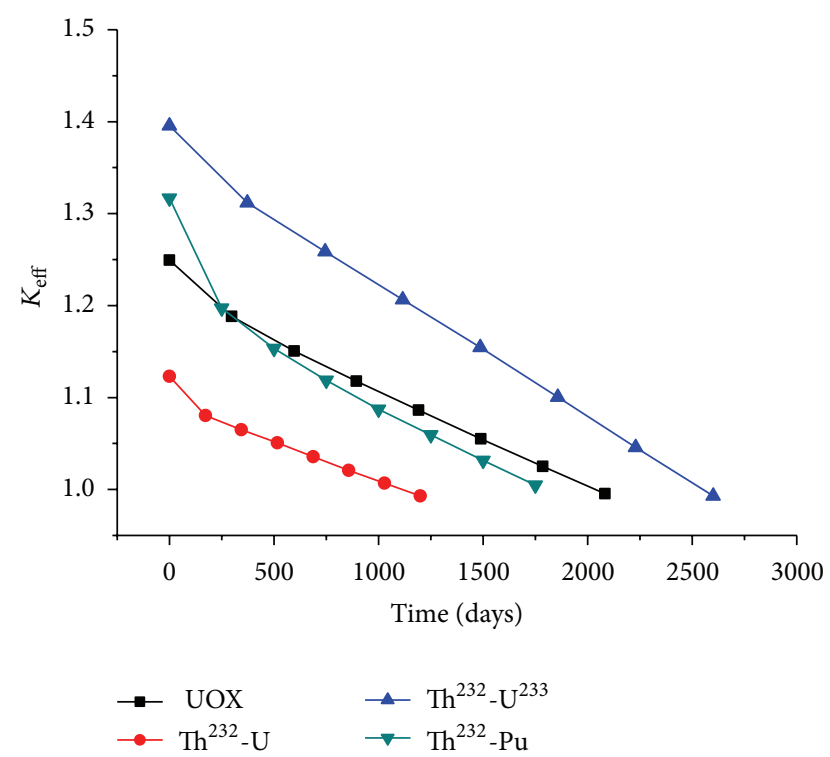

FIGURE 6: $K_{\text {eff }}$ evolution for the fuel cycles studied. and computer codes as well as its specific database: India, Israel, Japan, Republic of Korea, and Russian Federation. The benchmark was designed to compare assembly-level calculation methods, by defining a 2D lattice simulating a typical PWR fuel assembly.

The benchmark consists of a simplified model of a PWR assembly with a Plutonium-Thorium fuel composition. The model includes a $17 \times 17$ array of fuel rods, with 25 water hole positions without assembly casing and guide tubes (Figure 1). Burnup calculations were carried out with a constant specific power of $37.7 \mathrm{MW} / \mathrm{t}$ (initial heavy metal). Dimensions of the assembly and the material compositions of the fuel $(5 \%$ $\mathrm{PuO}_{2}+95 \% \mathrm{ThO}_{2}$ ), cladding (natural zirconium), and moderator (light water with $500 \mathrm{ppm}$ concentration of natural boron) can be found in [8].

We compared the results of criticality and fuel composition as a function of burnup (burnup range from 0 to $60 \mathrm{GWd} / \mathrm{t}$ ) with those obtained by the participants of the CRP. Table 1 and Figure 2 show the evolution of the multiplication factor during the burnup. Figures 3(a), 3(b), and 3(c) show 


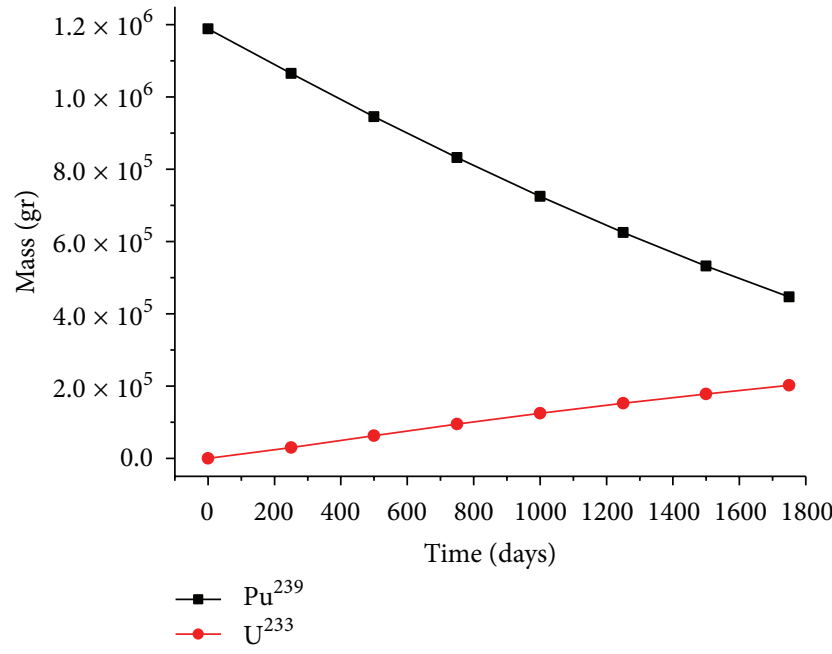

(a)

Figure 7: (a) Mass depletion of the fissile isotopes $\left(\mathrm{Pu}^{239}\right.$ and $\left.\mathrm{U}^{233}\right)$.

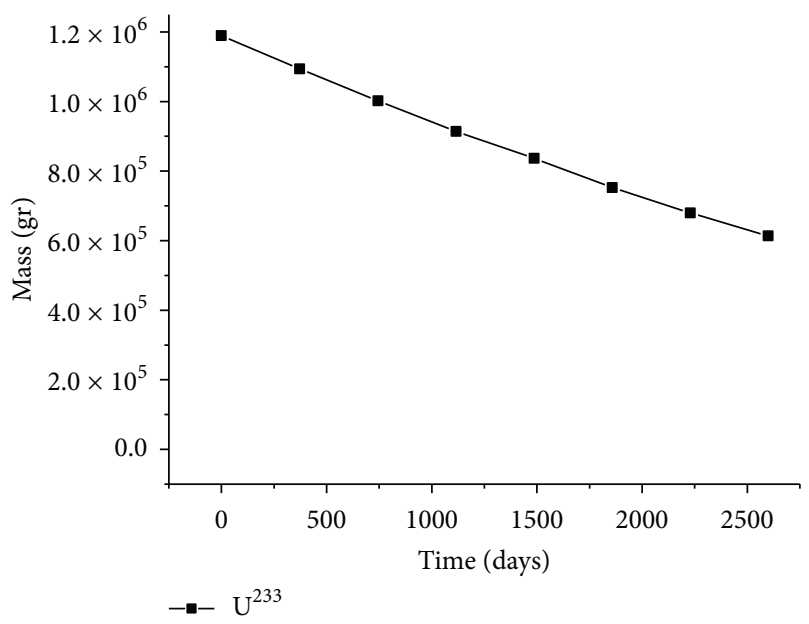

FIGURE 8: Mass depletion of the fissile isotope $\left(\mathrm{U}^{233}\right)$.

the relative concentration of $\mathrm{Th}^{232}, \mathrm{Pu}^{239}$, and $\mathrm{Pu}^{241}$ during the burnup. The results obtained from MCNPX version $2.6 \mathrm{e}$ code are in good agreement with the results of other participants of this benchmark and the discrepancies found correspond to those reported in [8]. These discrepancies can be caused by the use of various methods and nuclear database. Benchmark calculations performed contribute to the verification of MCNPX code for studies of thorium cycles in PWR and at the same time demonstrates the ability of the team in it use for burnup calculations.

\section{Models and Fuel Cycles Studied}

In this paper three thorium-based fuel cycles are presented and compared:

(i) $\mathrm{Th}^{232}+4.7 \% \mathrm{U}^{233}$, in this cycle one fissile isotope mainly sustain the criticality of the reactor: $U^{233}$, which represents a certain percent of the fresh fuel,

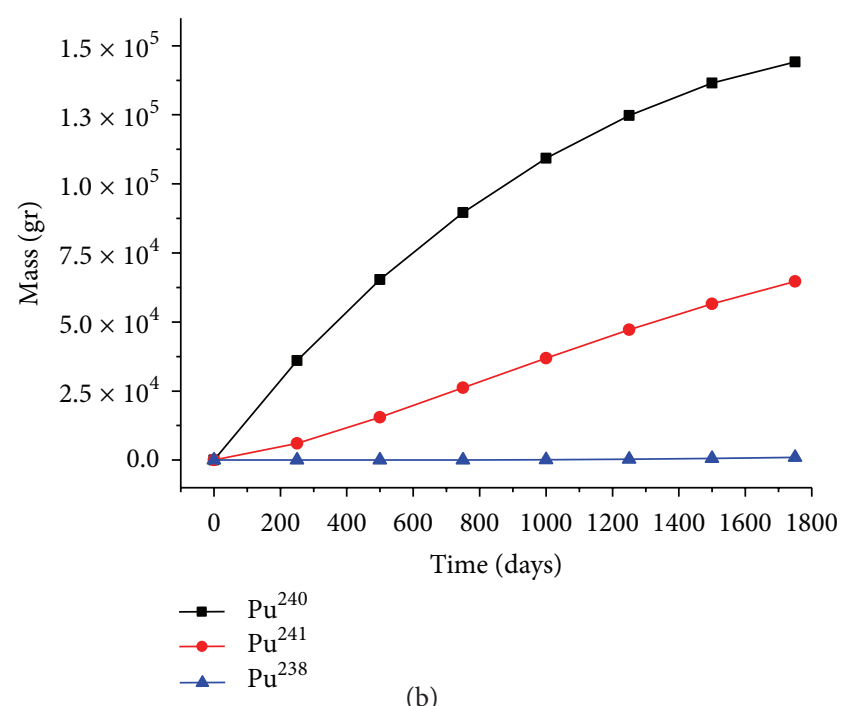

(b)

(b) Plutonium isotopes variation in the reactor $\left(\mathrm{Pu}^{238}, \mathrm{Pu}^{240}\right.$, and $\left.\mathrm{Pu}^{241}\right)$.

and the $\mathrm{U}^{233}$ produced by transmutation of fertile $\mathrm{Th}^{232}$.

(ii) $\mathrm{Th}^{232}+4.7 \% \mathrm{Pu}^{239}$, in this cycle two fissile isotopes mainly sustain the criticality of the reactor: $\mathrm{Pu}^{239}$, which represents a certain percent of the fresh fuel, and the $\mathrm{U}^{233}$ produced by transmutation of fertile $\mathrm{Th}^{232}$.

(iii) $40 \% \mathrm{Th}^{232}+60 \% \mathrm{U}^{238}$ enriched at the $7.83 \%$ in $\mathrm{U}^{235}$, in this cycle three fissile isotopes mainly sustain the criticality of the reactor: $U^{235}$, which represents a certain percent of the fresh Uranium, $\mathrm{U}^{233}$, which is produced by transmutation of fertile $\mathrm{Th}^{232}$, and $\mathrm{Pu}^{239}$, which is produced by transmutation of fertile $\mathrm{U}^{238}$.

Table 2 summarizes some of the main parameters of the TNPP VBER-150 concept in whole-core refueling mode used in the MCNPX calculation; detailed information about this reactor model (Figure 4) can be found in [13].

Three models of VVER-1000 assemblies were designed. The first one and second (Figures 5(a) and 5(b)) are an advanced VVER-1000 assembly with two different fuel element types. The thorium oxide fuel is placed into dark pins and the rest are fresh UOX pins. The third one, (Figure 5(c)) is the VVER-1000 assembly with one type of fuel pins; this assembly presents a homogeneous fuel distribution; in the three models the thorium oxide percent, enrichment, and $\mathrm{U}^{235}$ mass are the same.

The neutronic behavior of the reactor was studied as for burnup and cycle duration for the three models of distribution of the fuel element in the fuel assembly. As is shown in Table 3, the multiplicative properties are higher in the third model (fuel homogeneous distribution in the assembly), as well as the cycle duration in FPD; therefore, the burnup is relatively the highest. For this reason any posterior study presented in this paper will be made with the homogeneous model of fuel distribution. 


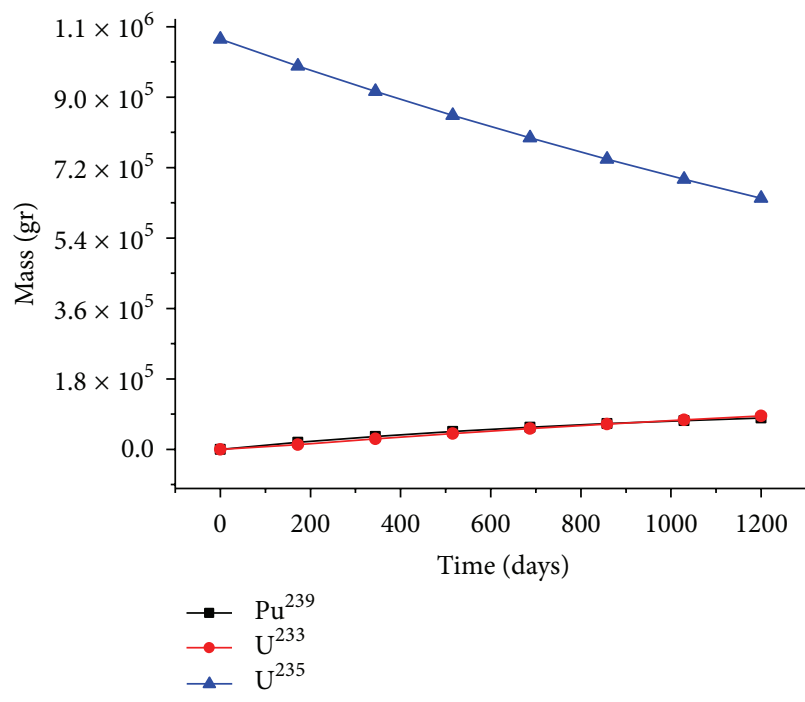

(a)

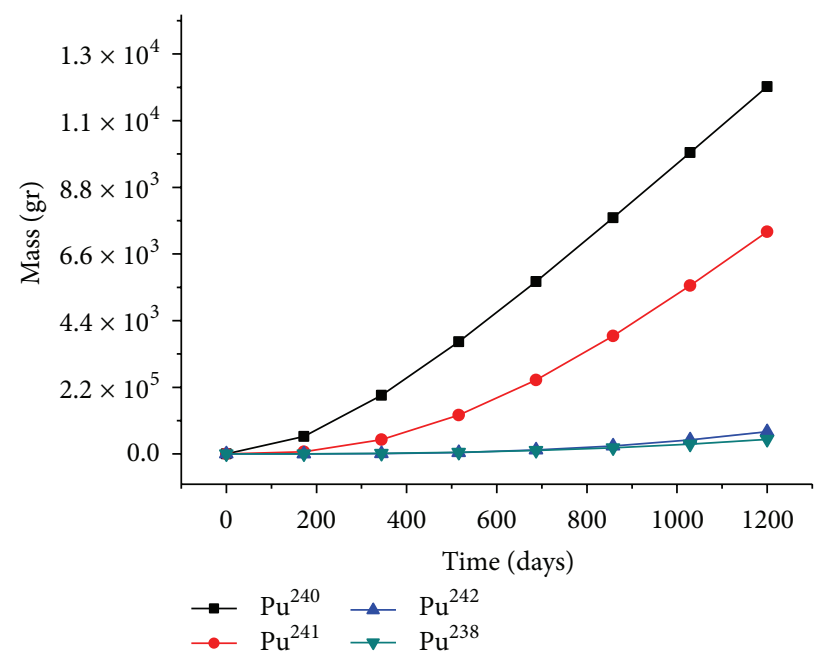

(b)

Figure 9: (a) Mass depletion of the fissile isotopes $\left(\mathrm{U}^{235}, \mathrm{U}^{233}\right.$, and $\left.\mathrm{Pu}^{239}\right)$. (b) Plutonium isotopes variation in the reactor $\left(\mathrm{Pu}^{238}, \mathrm{Pu}^{240}, \mathrm{Pu}^{241}\right.$, and $\left.\mathrm{Pu}^{242}\right)$.

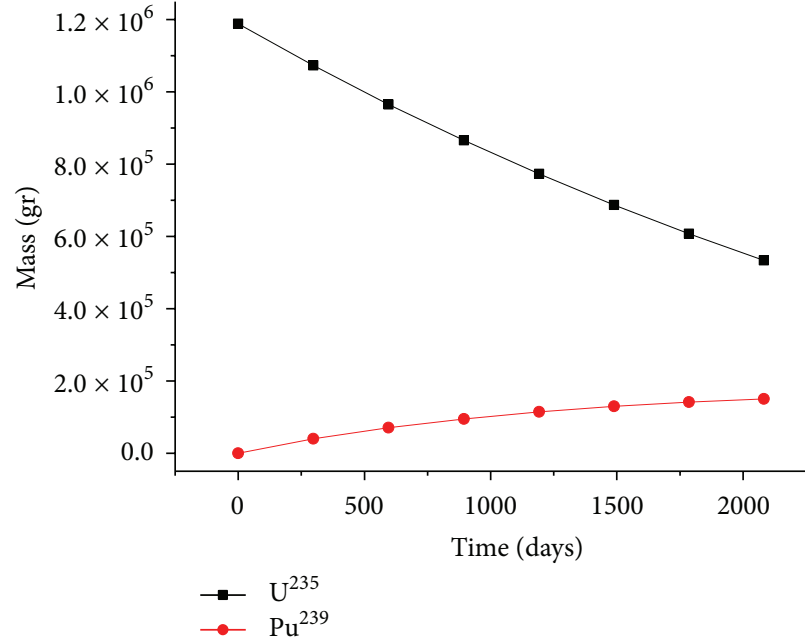

(a)

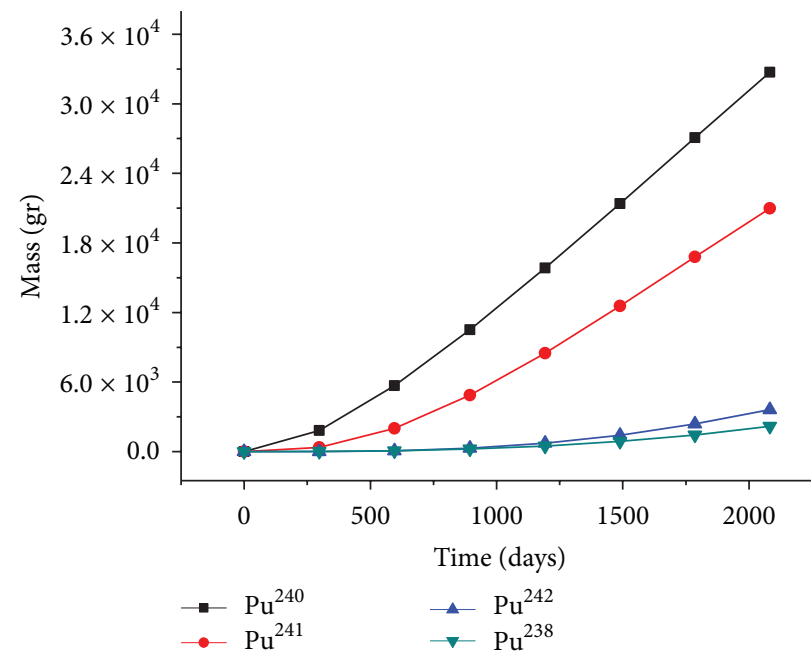

(b)

Figure 10: (a) Mass depletion of the fissile isotopes $\left(\mathrm{U}^{235}\right.$ and $\left.\mathrm{Pu}^{239}\right)$. (b) Plutonium isotopes variation in the reactor $\left(\mathrm{Pu}^{238}, \mathrm{Pu}^{240}, \mathrm{Pu}^{241}\right.$ and $\left.\mathrm{Pu}^{242}\right)$.

\section{Results}

The reactor behavior using the three-thorium-based fuels and the basic UOX cycles was modeled. The fuel burnup in the reactor was calculated using (1). The results of the discharge burnup, fuel cycle duration and $K_{\text {eff }}$ evolution can be seen in Table 4 and Figure 6:

$$
\text { Fuel burnup }(\mathrm{GWd} / \text { ton })=\frac{\text { Power }(\mathrm{GW}) \cdot \text { Time }(\text { days })}{\text { Fuel mass }(\text { ton })} \text {. }
$$

The results obtained for basic cycle of UOX are similar as those reported in [13] for this reactor; results obtained for thorium cycles support the use of thorium as fuel for this reactor. However, it is necessary to go deeper in safety studies regarding the thermomechanical behavior of the nuclear fuel and others.

The mass variation of the fissile isotopes and plutonium isotopes in the reactor as a function of time are shown in Figures 7(a) and 7(b) for $\mathrm{Th}^{232}-\mathrm{Pu}^{239}$ cycle, Figure 8 for $\mathrm{Th}^{232}$ $\mathrm{U}^{233}$ cycle, Figures $9(\mathrm{a})$ and $9(\mathrm{~b})$ for $\mathrm{Th}^{232}-\mathrm{U}$, cycle and Figures 10(a) and 10(b) for UOX cycle.

Figure 7(a) shows an important $\mathrm{Pu}^{239}$ decrease with respect to the loaded mass and it can be seen that the mass of $\mathrm{U}^{233}$ isotope presents a quasilinear growth. Figure $7(\mathrm{~b})$ shows that plutonium isotopes grow in all cases except in 


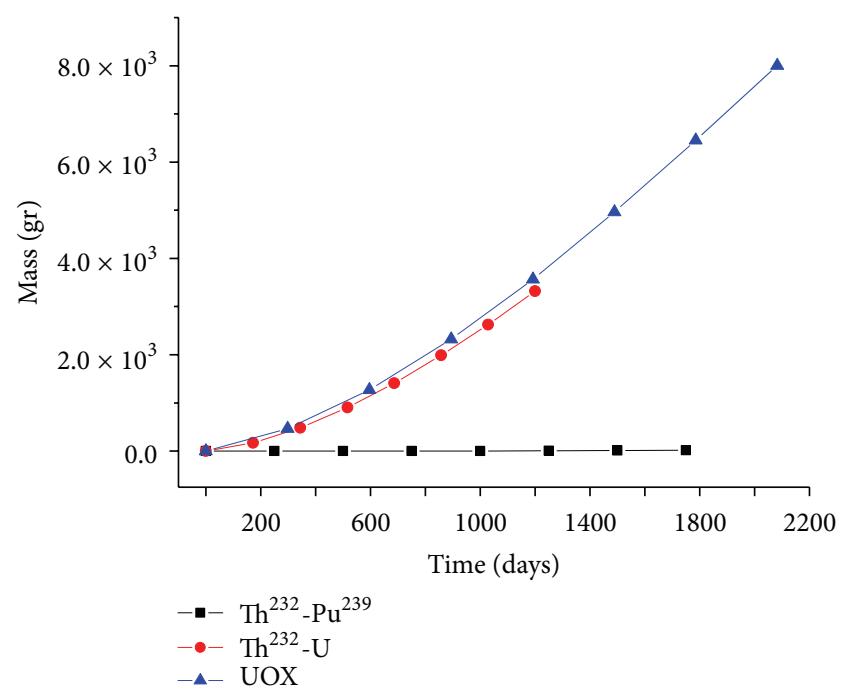

FIgURE 11: $\mathrm{Np}^{237}$ mass variation for the $\mathrm{Th}^{232}-\mathrm{Pu}^{239}, \mathrm{Th}^{232}-\mathrm{U}$, and UOX cycles.

$\mathrm{Pu}^{238}$. Figure 8 shows a light depletion of fissile isotope $\mathrm{U}^{233}$, product of the new $\mathrm{U}^{233}$ obtained from transmutation of $\mathrm{Th}^{232}$ isotope. In $\mathrm{Th}^{232}+\mathrm{U}^{233}$ cycle plutonium isotopes are not produced in the reactor. Figure 9 (a) shows $U^{235}$ decrease with respect to the loaded mass and it can be seen that the mass of $\mathrm{U}^{233}$ and $\mathrm{Pu}^{239}$ isotopes presents a quasilinear growth. Figure 9(b) shows that plutonium isotopes grow in all cases except in $\mathrm{Pu}^{238}$ and $\mathrm{Pu}^{242}$; in these two cases the plutonium masses presents a quasilinear growth. Figure 10 (a) shows $U^{235}$ decrease with respect to the loaded mass and it can be seen that the mass of $\mathrm{Pu}^{239}$ isotope tends to reach a constant value. Figure 10(b) shows that plutonium isotopes growth in all cases except in $\mathrm{Pu}^{238}$ and $\mathrm{Pu}^{242}$ in these two cases the plutonium masses presents a quasilinear growth. In all cases the fertile isotopes $\mathrm{U}^{238}$ and $\mathrm{Th}^{232}$ do not show important relative variation with burnup.

Table 5 presented the results of calculation of the fuel breeding coefficient (BC) values for the fuel cycles studied using similar approach proposed in [14]. The greater BC value is obtained for UOX cycle; however, important BC values were obtained for thorium cycles too; in these cases the final mass of fissile fuel left in the spent fuel is greater than UOX cycle. This is due to the quasilinear increase of the $\mathrm{U}^{233}$ mass in $\mathrm{Th}^{232}-\mathrm{Pu}^{239}$ cycle and $\mathrm{Th}^{232}-\mathrm{U}$ cycle (Figures $7(\mathrm{a})$ and 9 (a)) and the quasilinear decrease of the $U^{233}$ mass in $\mathrm{Th}^{232}$ $\mathrm{U}^{233}$ (Figure 8), while the mass of $\mathrm{Pu}^{239}$ is almost depleted in $\mathrm{Th}^{232}-\mathrm{Pu}^{239}$ cycle and the mass of $\mathrm{U}^{235}$ is consumed in a $40 \%$ in $\mathrm{Th}^{232}$-U cycle.

Figure 11 shows the mass variations of the minor actinide isotope $\mathrm{Np}^{237}$ in the reactor as a function of time for $\mathrm{Th}^{232}$ $\mathrm{Pu}^{239}$ cycle, $\mathrm{Th}^{232}-\mathrm{U}$ cycle, and UOX cycle.

Minor actinide which accumulates more is $\mathrm{Np}^{237}$; it is produced by neutron capture of $\mathrm{U}^{236}$ and subsequent beta disintegration of $\mathrm{U}^{237}$. Figure 11 shows an increase in the accumulation rate of this isotope in $\mathrm{Th}^{232}-\mathrm{U}$ cycle and UOX cycle, in $\mathrm{Th}^{232}-\mathrm{Pu}^{239}$ cycle $\mathrm{Np}^{237}$ mass is negligible.
In the $\mathrm{Th}^{232}-\mathrm{U}^{233}$ cycle insignificant masses of minor actinides isotopes are produced in the reactor.

\section{Conclusions}

The primary objective of this paper contribute to the neutronics analysis of the TNPP VBER-150 core, innovative concept currently in development.

The main objective of this paper is to examine the use of thorium based fuel cycle for the TNPP VBER-150 concept, in particular the neutronic behavior. The thorium based fuel cycles included $\mathrm{Th}^{232}+\mathrm{Pu}^{239}, \mathrm{Th}^{232}+\mathrm{U}^{233}, \mathrm{Th}^{232}+\mathrm{U}$, and the standard design fuel UOX. The $\mathrm{Th}^{232}+\mathrm{U}^{233}$ fuel cycle proved to be the best cycle for minimizing the production of Pu and MA in the TNPP VBER-150 concept. Also, it was demonstrated that a relatively low percent of fissile isotopes in the fuel mixture $(4.7 \%)$ is sufficient to design the reactor core with long operation cycles. Further studies are needed to confirm these results and contribute to development and demonstration of their technical, safety, and economic viability.

The neutronic calculations have been performed with the MCNPX version 2.6e code. Three different models of VVER-1000 assemblies were designed for the calculations with the purpose of selecting the model more suitable for the present study. Unfortunately there is insufficient data of VVER reactors with fuel containing thorium to validate the MCNPX code version 2.6e code. To reach this goal and considering the scope of this paper we performed calculation of the IAEA benchmark announced by IAEA-TECDOC-1349 for a simplified model of a PWR assembly with a plutoniumThorium fuel composition The results of benchmark calculations ratified that MCNPX code version 2.6e with available library in XSDIR, ENDF/B VI.2, is adequate for studies of thorium based fuel cycles.

\section{Acknowledgment}

Daniel Evelio Milian Lorenzo and Carlos Rafael García Hernández, project researchers CAPES-MES 114/11 "Estudo de sistemas nucleares avançados com combustível TRISO para a transmutação de rejeitos de longa vida e produção de hidrogênio com tecnologias de temperatura muito alta," thank CAPES (Coordenação de Aperfeiçoamento de Pessoal de Nivel Superior) of Education Ministry of Brazil for the financial support for this work.

\section{References}

[1] International Atomic Energy Agency, Legal and Institutional Issues of Transportable Nuclear Power Plants: A Preliminary Study, IAEA Nuclear Energy Series, IAEA, 2013.

[2] International Atomic Energy Agency, Monitoring and Surveillance of Residues from the Mining and Milling of Uranium and Thorium, Safety Reports Series, IAEA, 2002.

[3] International Atomic Energy Agency, Role of Thorium to Supplement Fuel Cycles of Future Nuclear Energy Systems, IAEA, 2012.

[4] International Atomic Energy Agency, Thorium Fuel CyclePotential Benefits and Challenges, IAEA, 2005. 
[5] International Atomic Energy Agency, Thorium Fuel Utilization: Options and Trends, IAEA, 2002.

[6] C. R. G. Hernández, A. M. Oliva, L. G. Fajardo, J. A. R. García, and J. P. Curbelo, "Uranium-thorium fuel cycle in a very high temperature hybrid system," in Proceedings of the International Conference on Mathematics and Computational Methods Applied to Nuclear Science and Engineering, Brasília, Brazil, 2011.

[7] The MCNPX Team, MCNPX User's Manual 2.5.0, LA-CP-050369, Los Alamos National Laboratory, 2005.

[8] International Atomic Energy Agency, Potential of Thorium Based Fuel Cycles to Constrain Plutonium and Reduce Long Lived Waste Toxicity, IAEA, 2003.

[9] J. Breza, P. Dař́lek, and V. Nečas, "Study of thorium advanced fuel cycle utilization in light water reactor VVER-440," Annals of Nuclear Energy, vol. 37, no. 5, pp. 685-690, 2010.

[10] International Atomic Energy Agency, Status of Innovative Small and Medium Sized Reactor Designs, IAEA, 2006.

[11] "Safety assurance of NPP with VVER," Recommendations of the 8th International Scientific and Technical Conference, Podolsk, Russia, May 2013, http://www.gidropress.podolsk.ru/ files/mntk2013/mntk2013-final.pdf.

[12] L. N. Andreeva-Andrievskaya and V. P. Kuznetsov, "Transportable nuclear power facilities in the INPRO International Project," Atomic Energy, vol. 111, no. 5, pp. 1-4, 2012.

[13] International Atomic Energy Agency, Status of Small Reactor Designs without On-Site Refueling, IAEA, 2007.

[14] C. García, J. Rosales, L. García et al., "Evaluation of uranium thorium and plutonium thorium fuel cycles in a very high temperature hybrid system," Progress in Nuclear Energy, vol. 66, pp. 61-72, 2013. 


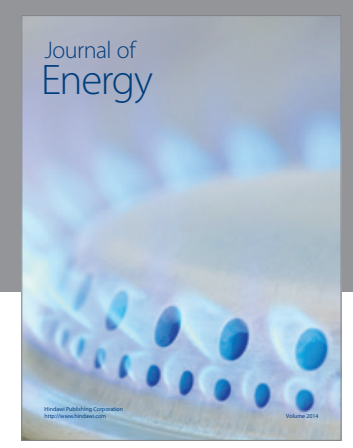

Journal of

Industrial Engineering
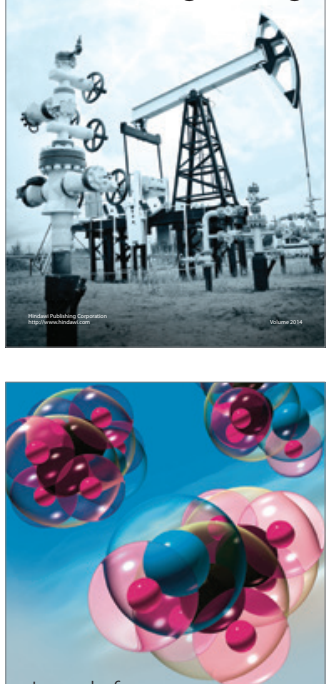

Fuels
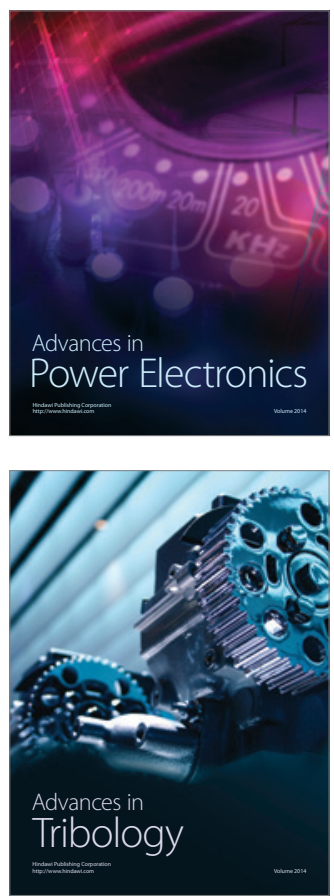

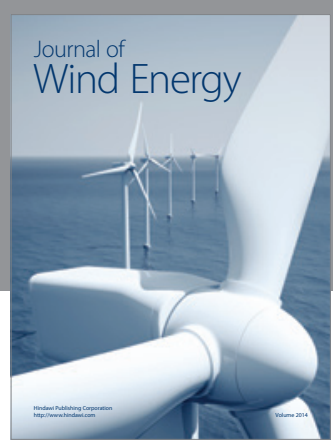

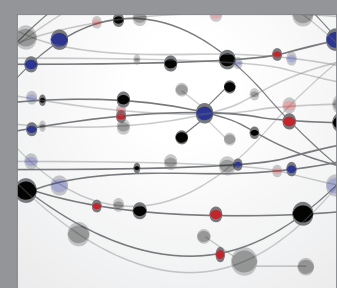

The Scientific World Journal

Submit your manuscripts at http://www.hindawi.com

Journal of

Structures
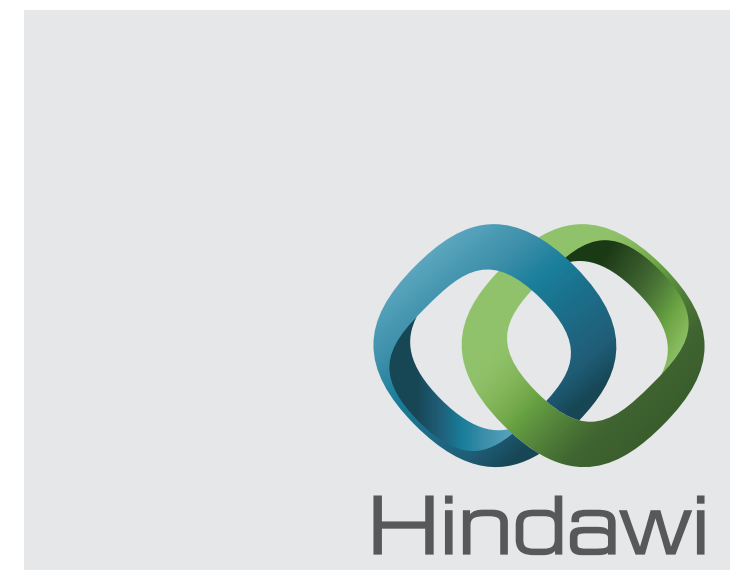

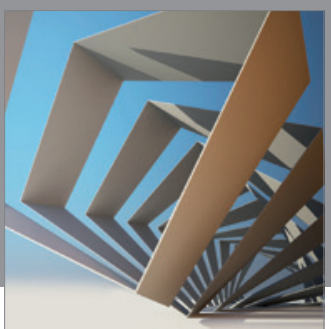

Rotating

Machinery
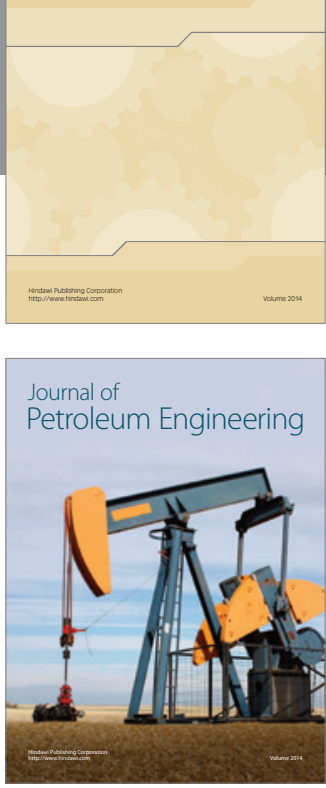

Journal of

Solar Energy
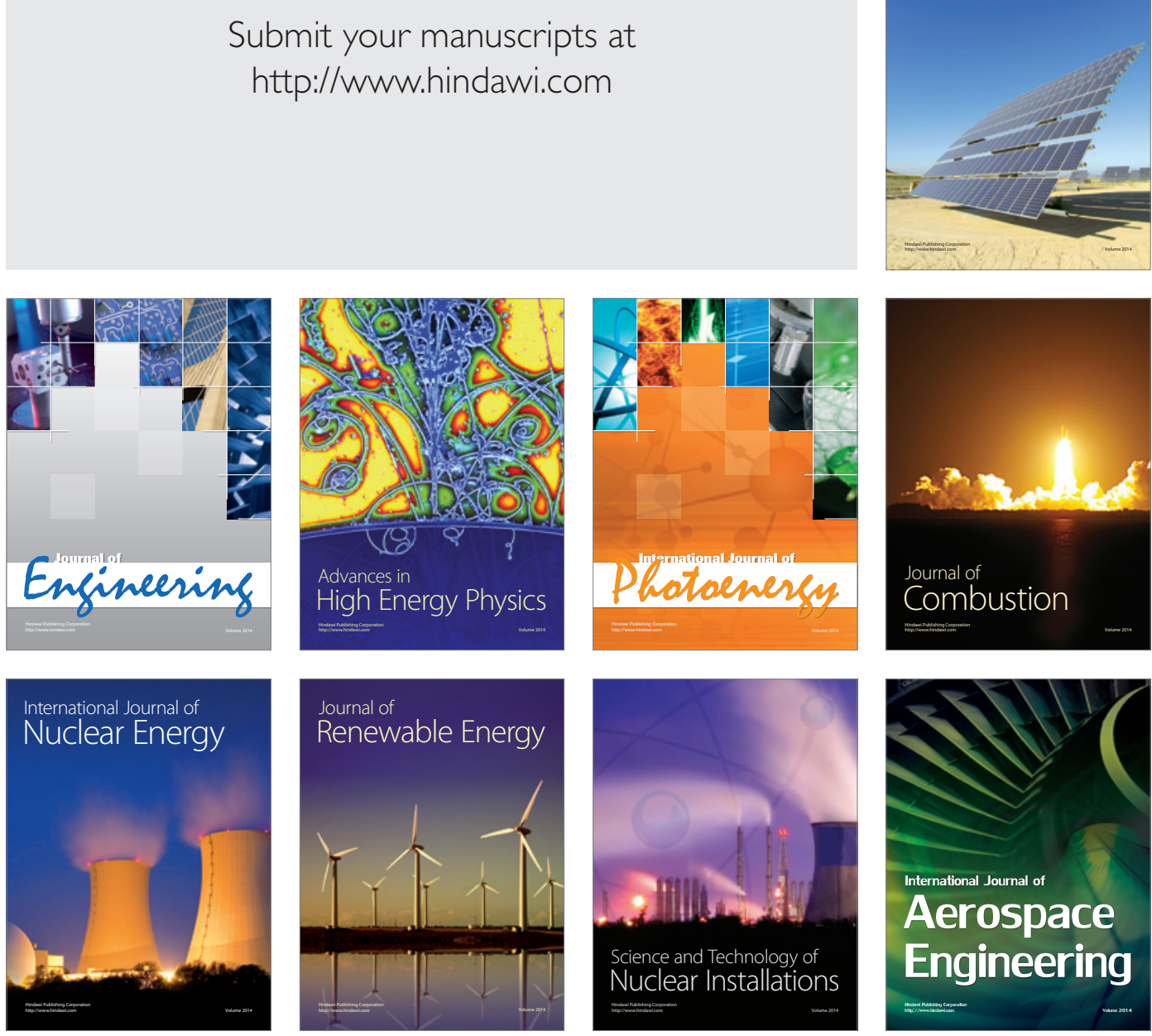